\title{
"EL UNO Y LA MULTITUD": CONFLITO DE IDENTIDADES . NUM TURBILHÃO DE PAIXÕES *
}

\author{
Profa. Dra. Maria Helena Rolim Capelato \\ Depto. de História - FFLCH - USP
}

\begin{abstract}
RESUMO: A novela do escritor nacionalista argentino Manuel Galvez El uno y la multitud (1955) constitui uma fonte historica extremamente rica para a reconstituição dos conflitos sociais e políticos ocorridos na Argentina no período que antecede o advento do peronismo. A análise desse texto literário possibilita mostrar a configuração de uma "identidade nacional coletiva", que permitiu aflorar uma nova forma de sensibilidade política na sociedade da época. A relação literatura/ história constitui o pano de fundo desta reflexāo sobre "sentimentos e identidade nạcional" na Argentina dos anos 1940.

ABSTRACT: The novel of the nationalist writer Manuel Galvez El uno y la multitud (1955) is an extremely rich historical source for reconstructing the social and political struggles in Argentina during the period which precedes the arrival of Perón in the political scene. The analysis of this book offers the possibility to discuss the issue of a "collective national identity" which enabled the birth of a new type of political sensibility. The relationship between literature and history is the basis of this analysis on "sentiment and national identity" in Argentina during the 1940s.
\end{abstract}

PALAVRAS-CHAVE: Peronismo, Identidade Nacional, Sentimento Político, Nacionalismo, Literatura e História.

KEY-WORDS: Peronism, National Identity, Political Sentiment, Nationalism, Literature and History.

Começou o ano de 1945, um dos mais transcendentais e agitados de nossa história. Anos de ódios, que vinham se acumulando desde o início da segunda guerra mundial $\mathrm{e}$ cuja iminente ferocidade havia se anunciado no transcurso do 44. Ano trágico, de permanente violência, ainda que não

- Este texto foi exposto, numa versảo preliminar, no Colóquio Internacional realizado na Unicamp, em maio de 1994 , sobre "Sentimentos e Identidades". de sangue, mas parecendo ressuscitar velhos e ardentes rancores entre federalistas e unitários. Ano de muitas calúnias, de perpétua angústia e inquietude, de ameaças, de divisōes nas famílias, de iradas palavras entre os amigos íntimos de ontem. Ano de inferno, de vida impossível, desagradável, histérica, raivosa...

Gervasio Claraval, do austero observatório de sua neu- 
tralidade, buscada e trabalhada, via a gigantesca luta de homens e paixões, de interesses, de esperanças, de coraçōes vingativos, de almas enlouquecidas pelo ódio. Em meio a essa luıa via o avanço das grandes massas prolelárias, da entrada em ação de um homem novo, que não era o homem da simples multidāo, de mithares de homens agregados uns aos outros, mas do homem que se sente formando parte da massa, que se move por um tremendo impulso pars adiante, que tem a consciência de seu poder, de sua justiça, de seus direitos contra o privilégio. Não era o velho povo dos políticos liberais, mas a moderna massa revolucionária (GALVEZ, 1955, p. 181).

Claraval é personagem da novela El uno y la multitud, de autoria de Manuel Galvez. O escritor argentino, engajado no movimento nacionalista católico de extrema direita que se consolidou no país nos anos 30 , aderiu ao peronismo por sc identificar com a sua política de justiça social.

A estória se inicia no período que antecede o golpe de 1943 (quando Perón se projeta pela primeira vez na cena política como Secretário de Trabajo y Previsión) e se encerra em 1945, logo após a vitória do movimento de 17 de outubro, data oficial do peronismo. Perón dias antes fora afastado de seu posto por pressão dos grupos liberais aliados à política norte-americana e de seus opositores no governo. Nessa data, retorna triunfante, com o apoio das massas operárias favorecidas por sua política trabalhista. $O$ episódio preparou o terreno para a sua eleição à Presidência da República em 1946, cargo para o qual foi reeleito $\mathrm{cm} 1951$, sendo deposto em 1955.

A leitura da novela de Manuel Galvez me estimulou a refletir sobre a questão-chave que orienta o enredo e bem tipifica as inquietações da época, ou seja, o conflito entre as noções de indivíduo e de massas que permeiam o confronto entre a política liberal e a política de massas introduzida pelo populismo peronista. No interior desse confronto situam-se também as posições nacionalistas de diferentes matizes que, a partir dos anos 20-30 colocam, para a sociedade argentina, a problemática da busca de uma nova identidade nacional coletiva.

A escolha deste texto literário para a análise de uma problemática política se justifica, também, devido à ênfase dada pelo autor aos sentimentos e paixōes que envolvem a sociedade argentina no momento em que se introduziu uma política de massas. É próprio do romancista preocupar-se com a reconstituição das emoções dos atores políticos individuais ou coletivos, mas Galvez carrega tanto nessas tintas que estimula o historiador a enfrentar o desafio de refletir sobre o significado da dimensão afetiva nessa experiência política.

O caminho aberto por Pierre Ansart (La gestion de passions politiques, 1983) é encorajador. Quero recuperar, no texto de Galvez, alguns elementos que demonstram a importância dos sentimentos políticos na política de massas. A novela em questāo sugere a hipótese de que uma nova forma de sensibilidade política se anuncia na Argentina com o advento do peronismo. Essa dimensāo afetiva merece scr explorada.

Ncsta exposição, pretendo investigar o modelo de identidade que se afirma na Argentina da época, vinculada a uma certa concepção de massa que passa a ser o centro da nova política.

O texto de Galvez é rico em imagens sobre a sociedade argentina. São imagens míticas mas reveladoras de sua visão de mundo e da realidade que ele captou. As figuras que ele cria fazem parte da realidade e contribuem para entendê-la.

O personagem Claraval, uma espécie de alter-ego do autor, expressa suas próprias angústias em face das transformações da sociedade argentina. Suas obras buscam mostrar as concep̧̧ōes de vários grupos sobre a realidade. Seus livros, lidos e aplaudidos por um público amplo, podem nos dizer algo sobre as esperanças e anseios dessa sociedade. Como diz G. L. Moosc, ao analisar o nacionalismo alemāo através de obras literárias, a literatura popular filtra as per- 
cepções humanas e coincide com muitas delas. Constitui, portanto, um meio vălido para entender a questão da identidade nacional, numa dimensão mais ampla.

Galvez era um autor popular. Considerado pela boa sociedade como um novelista sofrível, cujo mau gosto era comparado ao de seu público, as camadas médias recém constituídas, o autor alcançou sucesso pelo seu estilo. Com um programa oposto ao dos vanguardistas, preocupados acima de tudo com a estética, sua literatura de conteúdo, caracterizada por um realismo moralizador, atingia um público mais interessado nas estórias de conteúdo do que na estética dos renovadores (SARLO, 1988, pp. 189-195).

A literatura de Galvez tem função moralizadora mas também política. Na qualidade de intelectual, ele como outros nacionalistas, se colocava como intérprete do ser nacional.

A literatura argentina dos anos 20-30 procura, por caminhos diversos, responder a questões relacionadas à identidadc argentina. "Quem somos e como se constituiu a nossa diferença" é a pergunta que se impōe nos anos 20, persistindo até a década de 50. Ela suscitou polêmicas que envolviam posicionamento político-ideológico e concepçōes sobre cultura (Idem).

.Manuel Galvez teve vida longa (nasceu em 1882 e morreu em 1962). Mónica Quijada, ao analisar seus 60 anos de pensamento nacionalista, o define não como um político atjvo, mas pensador e observador comprometido com seus ideais. Testemunha, analista e crítico de uma sociedade cujo processo de transformação ele acompanhou ạpaixonadamente, produziu uma vasta obra que revela sua paixão pela Argentina e suas raízes. O hispanicismo, catolicismo e jus. tiça social, constituem as coordenadas de seu pensamento.

Descendente de uma tradicional família de políticos liberais da província de Santa Fé, transferiu-se no final do século para Buenos Aires, onde completou seus estudos. Aos 20 anos já manifestava interesse pela política, religião e questão social (QUIJADA, 1985, p. 7).

Buenos Aires, nessa época, passava por transformações muito significativas. $O$ afluxo massivo de imigrantes aí concentrados não só duplicou a população urbana mas modificou o perfil da cidade.

A Argentina se encontrava no auge de sua expansão econômica e Buenos Aires, florescente, com amplas avenidas e monumentos suntuosos, despontava como a capital cosmopolita. A imigração a transformara numa cidade de mezcla, como mostra Beatriz Sarlo em sua análjse sobre Buenos Aires.

A presença ostensiva do estrangeiro inquietava os "nativos". Manuel Galvez, como outros intelectuais de origem interiorana, sofreu o impacto da mudança para a cidade grande. Nunca se manifestou contra os imigrantes estrangeiros, mas a mezcla o perturbava. Em seus primeiros ensaios reporta-se à província como depositária de algo perdido para sempre nas cidades do litoral.

O autor reabilita a realidade depreciada pela geração anterior. Os liberais e positivistas haviam proclamado a luta da "civilização" (sociedade urbana) contra a "barbárie" (campo-interior). Șeu lema "governar é povoar" conduziu à política de imigração posta em prática a partir de meados do séc. XIX. A nova geração, onde se situa Galvez, orientou-se por um lema novo "governar é argentinizar". A busca de identidade nacional aqui se inicia com a afirmação do interior (espiritualista e purificante) frente ao cosmopolitismo (materialista). Além disso, a reivindicação de uma origem enraizada na Mãe Pátria-Espanha atuou como ferramenta unificadora da mezcla provocada pela imigração estrangeira, fazendo com que Yo y el otro se convertesse em nosotros.

Em sua obra El diario de Gabriel Guiroga (1910), considerada um dos pilares do primeiro nacionalismo argentino, Galvez mostrou preocupação 
com a descaracterização da Argentina provocada pela imigração massiva e influências forâneas na cultura e economia. Clama contra os desequilibrios entre o interior e litoral $a$ propöe um olhar para $o$ interior, em busca de valores morais e espirituais, esquecidos pelo progresso vertiginoso e afã de riquezas.

Os primeiros sinais de busca de uma nova iden. tidade já estão esboçados nessa obra.

$\mathrm{Na}$ década de 20, outras questões se colocam para a sociedade argentina. A Primeira Guerra causou efeitos negativos à cconomia do.país. A inflação $\mathrm{c}$ a diminuição de emprego provocaram distúrbios sociais. As greves se multiplicaram e o movimento de Reforma Universitária se alastrou por todo o país assumindo conotação social importante. A semana trágica de 1919 traumatizou a sociedade pelo número de mortos e violência da repressāo.

Além dos conflitos internos, as informações sobre a Revolução Mexicana e Revolução Russa fazem emergir a figura das massas no imaginário social: os partidários da esquerda se empolgam com o espetáculo das massas, os da direita, se amedrontam.

O movimento de Reforma Universitária foi interpretado como reprodução da Revolução Russa. A figura oculta dos soviets rondava entre os rebeldes. $O$ arcebispo de Córdoba interpretou o epiśdio como um dos aspectos da Revolução Mundial e conclamou os fiéis a orarem para que a tormenta encarnada por "massas ressentidas, sem freios e por mendigos mal agradecidos a seus benfeitores" fosse contida (BUCHRUCKER, 1987, p. 57).

A noção de massas relacionada à rebelião ou revolução permeia os escritos dos nacionalistas da época. A esquerda entendia que "o futuro é hoje" e a revolução social seria, sem dúvida, vitoriosa; para os que temiam as massas, a Revolução significaria a desagregação social.

Leopoldo Lugones, já nos anos 20 , alertava para esse perigo proclamando que chegara a "hora da espada". O país, invadido por uma massa estrangeira, disforme e hostil, enfrentava a ameaça coletivista. Apelava para o Exército como única salvação contra a revolta do populacho. Seu referencial era a Revolução Russa (Idem, pp. 58-59).

O tema do Comunismo se alastra na Argentina. Muitos acusavam o liberalismo e a democracia de haverem produzido esse monstro.

Um grupo de jovens católicos compartilhava desses temores. Leitores de Barrès e Maurras transportaram para a Argentina as lições do líder de L'Action Française, adaptando-as às condições locais. Em lugar da Monarquia, invocaram a presença de um caudilho para guiar as massas impondo ordem na sociedade. Esses jovens admiravam a obra de Galvez, que se juntou a eles nos anos 30 . Os nacionalistas católicos restauradores divergiam de Lugones por ser anticlerical, anglófilo, yancófilo e anti-hispânico.

Galvez recusava os movimentos de massa como a Revolução Mexicana e Russa mas, diferentemente de seus companheiros, que temiam as massas, considerava suas presenças c funçōes importantes. Eram perigosas agindo espontancamente, mas orientadas por um guia que promovesse a justiça social, tinham um papel legítimo na sociedade.

Nos anos 30, Galvez incorporou alguns clementos novos ao seu ideário: a recusa do estrangeiro (inglês ou norte-americano), o hispano-americanismo sob a égide da cruz e espada e a expectativa de apariçāo de um condutor guia para as massas. Mantevese fiel à idéia de justiça social.

Perón era o guia líder aguardado por Galvez. Militar enérgico, de punho forte, político eficiente e carismático, surgiu na cena política com uma proposta de amparar os desafortunados realizando justiça social.

Com o advento do peronismo foi introduzida uma nova perspectiva sobre as massas na Argentina. É o que procurarei mostrar na análise da novela de Galvez. Mas antes de me remeter ao texto, cabe avançar um pouco mais na caracterização dos problemas 
da sociedade e percepçōes sobre as massas vigentes no período que antecede ao peronismo.

Os temas do populismo peronista já se anunciavam nas obras literárias de autores como Raul Scalabrini Ortiz e Arturo Jauretche, ligados ao grupo FORJA (cisão do radicalismo Yrigoianista que, posteriormente aderiu ao peronismo). Os autores abordavam questōes como antiimperialismo, antioligarquia, sentimento de solidariedade coletiva e analisavam a sociedade pela perspectiva dos "de abajo" (SARLO, 1988).

Galvez, como católico, era anticomunista. Admirava Primo de Rivera, Mussolini e foi adepto do franquismo contra os republicanos que "incendiaram igrejas e templos na Espanha". Essas posiçōes o identificavam com o grupo nacionalista restaurador. Mas em certos aspectos, aproximava-se das concepções nacionalistas do grupo FORJA, distanciando-se dos restauradores. Enquanto a massa era vista por estes como perigosa, ameaçadora da ordem e causadora de decadência, para os forjistas, ela era valorizada por ser lutadora e capaz de provocar mudanças. Nessa perspectiva, entende-se que os caudilhos, representantes das massas populares deveriam se opor a uma classe dirigente egoista e entregue ao estrangeiro. Galvez concordava nesse ponto e na condenação do imperialismo inglês ou americano.

As divergências entre os nacionalistas dos anos 30 eram significativas, mas eles se uniam na espera do líder. Neste contexto, surge a figura de Perón: após o golpe de 1943 promovido pelo Grupo de Oficiais Unidos (GOU), o col. Perón foi nomeado Secretário de "Trabajo y Previsión" onde realizou obra social de destaque. Ao atender as reivindicações de uma parcela significativa do movimento operário, conseguiu o seu apoio.

O sucesso de sua política social granjeou-lhe inimigos dentro do governo e forte oposição dos setores liberais mais vinculados à política norte-americana. Esse grupo exigia participação da Argentina na guerra, junto com os Aliados. A postura de Perón
pró-Eixo e sua política de aproximação com as massas explicam a reação desses setores que tramaram sua queda em setembro/outubro de 1945. As manifestaçōes de massa permitiram o retorno triunfante do líder, no 17 de outubro, momento em que se consolida a política de massas do populismo peronisia.

Galvez tomou o partido de Perón e descreveu o epiś́dio de ascensão das massas na novela em questāo.

A partir da presença de Perón na política argentina, a busca de identidade nacional integrou a idéia de massa dando-lhe um novo sentido.

No discurso peronista, as massas sāo representadas pela imagem dos descamisados. Perón, identificandose com Jesus e seguindo seu exemplo, buscou seus amigos entre os pobres: os descamisados. Essa imagem está no cerne da justiça social promovida pelo líder.

O católico Galvez, que desde sua juventude se sensibilizava com a problemática de justiça social, identificou-se prontamente com a causa peronista.

Descamisado significava genericamente povo, massa, mas tinha um sentido pejorativo. Com Perón o termo é dignificado pela condição de amigo do líder.

$O$ autor peronista Pedro Geltman nos ajuda a esclarecer a relação identidade nacional/massa no projeto peronista. Afirma que esse projeto germinou baseado nas origens da nacionalidade. Encontrou sua expressão no homem desprezado do interior, que a classe culta chamava de cabecita negra. Chega a Buenos Aires, trazido pelo novo impulso de industrialização que provocou necessidade de mão-deobra. Foi aí desprezado culturalmente, até que encontrou um cauditho e um chefe por quem se sentiu interpretado. Por seu intermédio a sociedade rompeu com a antiga estrutura liberal copiada da Europa e Estados Unidos.

Pedro Geltman conclui que os dois tipos humanos ou ideais que se produziram no início da nacionalidade lutaram durante toda a história argentina e o último enfrentamento se deu entre peronistas e anti- 
peronistas. Os antiperonistas representando o primeiro ideal que olhava para a Europa, já então envelhecida, $\mathrm{c}$ o peronismo, representando as origens autênticas ligadas ao homem do interior, que nesse momento encontrava condições de se desenvolver (ǴELTMAN, 1973, pp. 126-127).

Essa polaridade indicada pelo autor constitui traço importante na construção da identidade coletiva. É pelo contraste com o outro que a nova identidade proposta pelos nacionalistas e reelaborada pelos peronistas se afirma, impondo segurança face aos temores de desintegração da nacionalidade e da söciedade.

A novela de Galvez não se insere no rol da literatura de propaganda que incorpora o mito peronista $e$ o reproduz à exaustāo. $O$ autor descreve, com grande entusiasmo, o movimento das massas em ação, mas revela os conflitos, esperanças, temores vivenciados pela sociedade argentina num momento de extrema turbulência, que deixou marcas profundas no imaginário e história do país.

$O$ trecho de abertura desta exposição evidencia as paixões que o movimento de massas peronista despertou na sociedade. Ninguém ficoù indiferente a cle. $O$ autor viveu, com intensa emóção, essa época e a descreve estimulado pélos sentimentos que captou e sentiu.

$\mathrm{A}$ angústia que acompanha Claraval revela um conflito entre séu eu individual e coletivo; suas dúvidas, temores, esperanças frente ao movimento das massas, traduzem as perturbações do próprio autor.

Galvez apoiou o peronismo mas a sua formação individualista provocava sentimentos de incerteza face à realidáde nova que exigia adesāo total ao líder e integração completa na massa. A resistência do aútor a esse tipo de compromisso perpassa o texto, que deixa implícita uma tensão constante.

Em meio a oligarcas e políticos corruptos que fazem alianças com os imperialistas ingleses e Yankes, mulheres aristocráticas que se aliam a operários co- munistas, feministas socialistas que transitam entre Moscou e a Casa Branca, operários comunistas que visitam o Embaixador norte-americano, católicos que aderem ao liberalismo $\mathrm{c}$ se juntam aos ricos contra os pobres, desponta o quadro que o autór retrata do movimento de Frente Ampla. Esse movimento, que tem como bandeira o antifascismo e a entrada da Argentina na guerra ao lado dos Estados Unidos, opôs-se ao movimento peronista e foi responsável pela queda de Perón em 1945. Os grupos integrantes dessa Frente constituíram a União Democrática que, na dispula presidencial de 1946, lançou o candidato de oposiçāo a Perón. O Embaixador americano, Braden, destacou-se na campanha anti-peronista. A novela mostra que, do lado de Perón, estão as massas sem rosto, cara invisível do líder e responś́veis pela sua vitória. Segundo o narrador, elas triunfam.

Os nacionalistas católicos apoiaram Perón. Tito, fitho de Claraval, representa esse grupo. O jovem es.' tudante de medicina se destaca pclo fanatismo politico; envoive-sè até às últimas conseqüênicias no movimento de massas peronista.

Claraval é espectador dos acontecimentos e só adere ao movimento no auge de sua efervescência. Representante de uma geração que cultuou o individualismo, a razão $\mathrm{e}$ a liberdade, sente seus valores $\mathrm{e}$ convicçõcs sc ábalarem diante das experiências vividas pelo filho. Tito é expressão da nova geração que pôs $\mathrm{cm}$ xeque o arcabouço das idéias liberais, contestou o poder oligárquico e a exploração imperialista.

O diálogo entre os personagens traduz bem os conflitos da época. Os odiosos "cipayos" (aliadófilos) se degladiam com os odiosos "nazi" (nacionalistas) desde o início dos relatos.

O narrador comenta que, no outono de 1944 , as paixões haviam chegado ao ponto máximo em dècorrência da entrada da Argentina na guerra.

Numa das inúmeras discussões familiares aflora o tema da identidade argentina que bem mostra o teor das divergências políticas. 
Para Albano, o tio americanofilo de Tito, a identidade se define pela geografia: "A América é uma só. Não se pode negar a unidade da América e o direito dos Estados Unidos de ser uma naçāo líder no continente. Devemos agradecer-lhes que projetam todas as republiquetas hispano-americanas que nem direito de existir tem".

Tito retruca: "a geografia não tem valor". Invoca a raça, o sangue, a religião, o idioma como elementos constitutivos da nacionalidade. "Nós somos espanhôis", afirma o jovem nacionalista.

O tio contra argumenta recordando a história: "a Espanha exterminou os índios, nos impôs um sistema de opressão, nos legou o atraso, por isso somos um povo retardatário" (GALVEZ, 1955, pp. 25-26).

A contenda em torno das velhas teses dos liberais e novas idéias dos nacionalistas define os dois sentidos da identidade nacional.

Claraval nāo se posiciona frente a essa dicotomia. O conflito que o atormenta é de natureza diversa: suas dúvidas se concentram $\mathrm{cm}$ torno da relação indivíduo/multidão.

Segundo o narrador, esse tipo de conflito entre o ser humano e a massa, cntre o indivíduo e a multidão, não existia nas pequenas cidades. Manifestava-se $\mathrm{cm}$ Buenos Aires, a grande urbe de três milhões de habitantes, cenário onde a estória se desenrola.

Claraval vive intensamente a angústia da divisão entre o ser uno c colctivo. Sua formação o impelia ao recolhimento no eu individual mas a vida na grande cidade não o permitia ignorar a presença da multidão. Sente diante dela temor e fascínio; às vezes chega a desejar submergir nas ondas humanas.

Nessc ínterim, ocorre o golpe de 1943 que possibilitou o advento da política de massas de Perón.

Tito, eufórico com a vitória do golpe, entrou em casa, abraçando e beijando os pais; logo explica o que era o GOU.

A partir desse episódio, a sociedade começa a se dividir e a divisão se aprofunda na família de
Claraval. Tito e seus tios, Flávia e Albano, se colocam em lados opostos da trincheira.

Flávia se integra na Frente Popular onde entra em contato com membros do Partido Comunista. O antifascismo uniu inimigos de classe e dessa união resultou o romance clandestino de tia Flávia com o líder operário comunista de nome Germinal. A alusão ao Germinal de Zola é evidente e significativa (Idem, p. 103).

O operário comunista representa uma parcela da massa trabalhadora que o autor católico sente como inimiga. O nome Germinal sugere a imagem de uma massa violenta, perigosa, besta selvagem, que uma vez desacorrentada não se pode impedir de massacrar. A multidão delinquiente de Zola é perigosa porque capaz de destruir a ordem da sociedade e acabar com a religião. Germinal, o comunista, é a expressão do inimigo número um dos grupos nacionalistas católicos.

$O$ adultério da tia é duplamente criminoso e pecaminoso. Ameaça a ordem religiosa/moral e social.

O espetáculo da multidão se amplia e se modifica com a presença de Perón na Secretaria do Trabatho. Conta o narrador que, por toda parte, se comentava ter chegado "a hora dos pobres".

Claraval continuava refletindo sobre o seu dilema:

A vìda em multidão, na cidade grande, parecia horrivel para o homem que se formou na existência individualista, mas segundo tudo indicava, a derrota do homem era inevitável. Tudo agora se fazia em função da massa: gigantescos edifícios, cidades imensas, universidades populares. Até a cultura, a dimensão mais individual da vida, esquecera o homem para dirigir-se à massa. Era o fim do humanismo que se refugiaria nos conventos. (ldem, p. 126)

Viver vida coletiva significava, para Claraval, converter-se numa infinita partícula da massa. Perder a individualidade implicava, num certo sentido, perder a alma. 
Galvez aborda o problema da multidão em várias dimensões. Neste trccho ela não tem conotação política. Está se referindo às aglomerações das grandes cidades, labirinto onde os seres abandonam sua identidade singular, dispersando-se entre centenas de seres com os quais seu destino parece confundir-se.

Esse tema é tratado por uma vasta literatura que reconhece nas grandes cidades curopéias do século XIX (Paris, sobretudo) o retrato de uma multidão onde as almas solitárias se dispersam. A fragmentação, atomizaçāo e perda da identidade individual das Luzes se coloca como um problema para geraçōes do século XIX.

A literatura argentina dos anos 20-30, enfrenta essa questão. As transformações que ocorrem na cidade de Buenos Aires no início do século faz com que os intelectuais $\mathrm{cm}$ geral $\mathrm{e}$ litcratos em particular se voltem para a problemática das massas na cidade grande e os problemas decorrentes dessa transformação da realidade urbana'.

Veremos, a scguir, como em outros momentos da obra as referências às massas tem conotação bem diferente.

Com Perón na Secretaria do Trabalho, "realiza-se um primeiro de maio pacífico". O narrador refere-se a uma manifestação gigantesca. "Pela primeira vcz as massas proletárias vão às ruas apoiar o governo", o

1. Beatriz Sarlo, em Una modernidad periférica. Buenos Aires 1920-1930 (1988), cstuda as nudanças que ocorreram na sociedade argentina a partir das transformações urbanas que alteraram os códigos de referência e o modo de percepçło do espaço urbano. A autora mostra o lugar da cultura nessa sociedade atravessada pela mensagem dos meios de comunicação massivos (jomais, cinema etc.): mostra, tanbém, como a formação de camadas médias modificou o perfil do público e consolidou um mercado editorial local. Além das revistas de grande tiragem, surge um novo público, mais amplo e menos exigente na literatura. As obras de Galvez têm receptividade nesse campo. Seus livros retratam os dilenas provocados por essas mudanças que transformaram a sociedade e cultura argentina numa sociedade de cultura de massas. que representa indícios de uma nova era da política (GALVEZ, 1955, p. 130).

$\mathrm{O}$ individualista Claraval começa a se entusiasmar com essa revolução social pacífica. As massas proletárias do primeiro de maio de Perón não são as massas proletárias do Partido Comunista, que prega a revolução pela violência.

Os conflitos de rua se intensificam nos meses seguintes. 1945 sc anuncia, na novela, como um ano de ódios e grandes conflitos.

Segundo o narrador, Claraval os observa com neutralidade mas a descrição das massas, relatada no início da exposição, mostram um novo sentimento e uma nova abordagem face à multidão. Nāo se trata, como diz o narrador, de simples multidão, agregação de milhares de homens mas "do homem que se sente fazendo parte da massa, que se move, por instinto, para a frente c que tem consciência do seu poder". Essa multidāo tem caráter nitidamente político. $\mathrm{O}$ autor entra também no âmago da questão social: o conflito retratado é político e social.

Claraval contempla a épica luta dos operários e de certos núcleos nacionalistas contra a força poderosa internacional do liberalismo que se mobilizou no mundo todo contra nós, que nos ameaçou com seus grandes canhōes. Coloca-se como observador da luta social, de classes. Mas o nós do final da frase denota a identificação do autor com a questão nacional. $O$ personagem se integra no nós (argentinos) contra o outro (os liberais aliados dos imperialistas). O nós é representativo da identidade nacional, coletiva.

$\mathrm{Na}$ descrição da luta social das massas proletárias, a imagem da nova multidão fica nítida. A massa se move por impulso mas é racional: tem consciência do seu poder, justiça, direitos e se opõe aos privilégios.

O narrador esclarece: "Não era o velho povo dos políticos liberais, mas a moderna massa revolucionária" (Idem, p. 181). Essa distinção entre o povo dos liberais e a massa proletária é bem significativa. Essa 
massa não é uma soma de destinos individuais; ela é a expressão do coletivo. A luta se trava, não entre indivíduos mas entre classes ou grupos. O social é a mediaçāo do conflito. Mas a identidade singular ou de classe desaparecem no discurso nacionalista que enfatiza a identidade coletiva.

No relato dos conflitos, o narrador situa a posição do governo que tenta implantar a justiça social: "as massas apoiam as autoridades em gigantescas manifestações nunca vistas em Buenos Aires até então". A manifestação em apoio às autoridades governamentais ganha legitimidade porque não representa perigo: as massas estão sob controle.

Há grande ódio entre os argentinos, observa Claraval. Explica que ele é estimulado pelos norteamericanos e se deve também ao avanço da obra social de Perón que deixava fora de si os industriais, estancieiros, os ricos $\mathrm{em}$ geral e também os líderes dos partidos.

Claraval nada sabia sobre Perón mas começava a sc impressionar com suas palavras: "queremos que desapareça do país a exploração do homem pelo homem, que igualemos um pouco as classes para que não haja no país homens demasiado pobres nem demasiado ricos", dizia o líder (Idem, p. 185). A cssência da justiça social aí transparece, marcando o divisor de águas cọm o projeto comunista. A igualdade total dos comunistas se contrapõe a igualdade relativa dos peronistas. Um pouco mais de igualdade não abala a ordem social, ao contrário, a reassegura.

Galvez, que desde jovem se mostrava entusiasta da doutrina social da Igreja, não poderia deixar de aplaudir as idéias de Perón. Mas o projeto de "menos ricos e menos pobres" provocou grandes distúrbios que culminaram nas manifestações do 17 de outubro.

"Nesse dia surgiu algo muito grande", diz o narrador. "Amado por uns c odiado por outros, mas indiscutivelmente muito grande, princípio de uma Revoluçāo Social: o verdadeiro levante das massas."
A preparação do movimento assusta Claraval, que continua como espectador do processo, dividido ainda entre seu eu individual e coletivo.

Confessa à mulher que pressente o anunciar da Revolução Social. "Sente-se no ar. Tenho uma sensibilidade estranha para esses fenômenos coletivos. E temo que seja sangrenta."

A dimensão afetiva da percepção se sobrepõe à racional. Aqui se nota outro tipo de conflito que o personagem enfrenta: a dualidade entre o sensível e o racional. Claraval intui a Revolução no terreno da emoção, sente medo. Mas a explicação do temor se dá pela argumentaçāo racional.

Explica à mulher:

As Revoluçōes Sociais nāo sāo tranquïilas. Recordese da Russa, da Mexicana. A multidão é uma fera de milhares de cabeças. Nunca falta quem fale a um grupo de ignorantes, assegurando coisas como verdades documentadas. E em seguida, cem bárbaros e depois duzentos mais e logo milhares saem a matar, apunhalar, degolar. Assim é a multidão enraivecida. Por isso creio que veremos coisas horriveis. Não sairemos por nada (Idem, p. 250).

A sugestibilidade e influência, noçōes básicas da psicologia das multidōès estāo implícitas na explicação de Claraval. Quando esclarece o pórquê dos perigos, os autores da tese sobre a multidão criminosa se reconheceriam na sua argumentação. Sighele, por exemplo, considerava a multidāo criminosa por ser composta de homens delinqüentes que, encolerizados, atacavam, como bestas feras, ferindo, destruindo: O seu comportamento é imprévisível e incontrolável.

Cabe aqui a pergunta: por que Claraval, que já demonstrara simpatias ao movimento das massas, agora manifesta temor e recorre à imagem da multidão criminosa?

Cabe lembrar que o 17 de outubro foi articulado pelos líderes peronistas: eles organizaram o movi- 
mento nos mínimos detalhes e Eva Perón teve aí papel de destaque. Mas a manifestação aparece como natural, espontânea, de iniciativa das próprias massas. Os conservadores estudiosos do fenômeno das massas advertiam que a massa sem liderança constitui perigo, é incontrolável e imprevisível. Os temores que a massa sem líder provoca se explicitam nessa fala de Claraval.

Mas os seus medos não se concretizam; o autor quer, com isso, enfatizar a natureza pacífica do movimento e assim prepara o terreno para a integração de Claraval na massa.

"No 17 de outubro, milhares de operários penetram na cidade. Era o começo da Revolução", diz o narrador (Idem, p. 25I).

As notícias sobre os números eram alarmantes. Uns informavam que hordas degolariam pessoas decentes, incendiariam casas e violariam mulheres. Outros diziam que o governo poderia liquidar, à bala, os rebeldes.

Claraval, junto ao rádio, inteirava-se, não sem nenhum assombro, do despertar das massas e se desespera por não poder presenciar a manifcstação. Nesse instante, a atração pelo espetáculo sobrepuja o medo que definiu sua atitude de recolhimento no espaço privado do lar. O conflito parecia estar prestes a se resolver. Decide-se pelo espaço público - vai as ruas misturar-se às massas.

Espremido, no meio da massa assiste à apariçāo de Perón no balcão da casa de governo. O Presidente Farrell anuncia "outra vez junto a vocês, o homem que soube ganhar o coração de todos". O mundo parecia vir abaixo. Delirantes exclamações (Idem, p. 255).

Claraval, angustiado e tremendo de entusiasmo face à multidāo, estava contente pelo espetáculo grandioso que assistia, mas desgraçado pelo desconforto que experimentava. Sentia-se oprimido, enfermo de multidão. Ele, que sempre buscara a solidão, fora se meter ali. No entanto, não tinha deixado de estar só em meio a esse mar humano, sem uma alma com quem se comunicar. Ali não havia almas individuais, senão a alma única, a alma multitudinária. Mas ele não se considerou submerso, desaparecido nela. Opinava como ela, mas nāo scntia como ela, nāo vibrava como ela. O dilema de Claraval nāo se resolve. Admira o movimento mas não se integra nele. Ao deixar a multidảo, comenta com a família c amigos: "Pressinto que cssa jornada será histórica. Tenho a certeza de que começou uma verdadeira Revolução Social". Comenta, também, que a multidāo não se comportara como besta fera como chegara a temer. "Eram revolucionários alegres que cumpriam sua obra rindo e cantando" (Idem, p. 256).

A multidão pacífica e a presença do líder conferem segurança e legitimidade à Revolução Social.

A imagem do povo feliz tão propalada pelo mito peronista se anuncia na fala de Claraval. Mas o final da obra, como o final da vida de Galvez mostram que o autor nunca aderiu completamente ao mito.

No final da novela, o nacionalista Tito, desiludido consigo próprio e com a vida, renuncia a tudo: carreira, atividade política, casamento, família. Entra para o convento dos beneditinos, tornando-se monge.

$O$ autor terminou de escrever a novela em 1953, época em que o segundo governo de Perón já dava sinais visívcis de esgotamento. $O$ governante enfrentou crise econômica e crise política que abalaram sua popularidade. O conflito com a Igreja e posterior rompimento fez com que perdesse $o$ apoio dos católicos; Galvez frustou-se com o peronismo. O otimismo inicial cedeu lugar a uma profunda decepção, não só com o peronismo, mas com os projetos de futuro para a sociedade. Nos últimos anos de sua vida vislumbra o ocaso da Argentina. Anteviu tempos novos, tempos horríveis, apocalípticos. $O$ autor se voltou para a busca da redenção, através da religião mística. O caminho de Tito e o de Galvez se cruzam no final da novela e da vida do autor.

Galvez acompanha e descreve, com paixão, as transformações da Argentina. Entusiasmou-se com 0 
peronismo, mas recusou o projeto de adesão total ao líder e anulação da individualidade na massa peronista.

A novela mostra bem como o sentimento e as paixões cimentam a construção mítica da identidade coletiva peronista, onde a massa desponta como redentora. Mas os conflitos que atormentavam o autor (universalismo/humanismo X particularismo e individualismo $X$ coletividade) impediram que sua visão da historia se reduzisse ao mito. A novela de Galvez permite que se vislumbre a luta política e social. $\mathrm{O}$

\section{Bibliografia}

"Masses et Politique". Revue Hermes n.2, Paris, Ed. du CNRS, 1988.7 Moscovici, Serge. L'Age des foules, Bruxclles, Eds. Complexe, 1981 .

ANSART, Pierre. La gestion des passions politiques. Lausanne, L'Age d'Homme, 1983.

BUCHRUCKER, Cristián. Nacionalismo y peronismo. Buenos Aires, Editorial Sudamericana, 1987.

GALVEZ, Manuel. El uno y la multitud. Buenos Aires, Alpe, 1955. autor apresenta ao público leitor as questōes-chaves da época: a questão social, a busca de identidade nacional coletiva e a incorporação das massas a ela. Aqui estão os temas articuladores do enredo.

As alianças contraditórias, as polêmicas ideológicas e políticas nas quais se lançam os personagens representantes de grupos em lutas, as esperanças e temores que os movem e as imagens diversificadas da mulıidão que o texto apresenta, permitem ao historiador desvendar, através da novela, a complexidade do social.
GELTMAN, Pedro. "Mitos, simbolos y héroes en el peronismo". In: El peromismo. 2 ed. Buenos Aires, Ediciones Cepe, 1973. LACONE-LABARTHE, Philippe \& NANCY, Jean-Luc. Le mythe nozi. Marseille, Editions de l'Aube, 1991.

QUIJADA, Mônica. Manuel Galvez: 60 años de pensamiento nacionalista. Buenos Aires, BPA-CEAL, 1985.

SARLO, Beatriz. Una modemidad periferica: Buenos Aires, 1920 - 1930. Buenos Aires, Eds. Nueva Visión, 1988. 